\section{$\underset{\text { hommes }}{\text { \& migrations }}$}

\section{Hommes \& migrations}

Revue française de référence sur les dynamiques

migratoires

1302 | 2013

Le Japon, pays d'immigration?

\title{
Frédéric Ciriez, Mélo
}

Paris, Verticales, 2013, 325 p., 20,00€

\section{Mustapha Harzoune}

\section{Q OpenEdition \\ 1 Journals}

\section{Édition électronique}

URL : http://journals.openedition.org/hommesmigrations/2527

DOI : 10.4000/hommesmigrations.2527

ISSN : 2262-3353

\section{Éditeur}

Musée national de l'histoire de l'immigration

\section{Édition imprimée}

Date de publication : 1 avril 2013

Pagination : 195-196

ISBN : 978-2-919040-22-3

ISSN : $1142-852 X$

\section{Référence électronique}

Mustapha Harzoune, « Frédéric Ciriez, Mélo », Hommes \& migrations [En ligne], 1302 | 2013, mis en ligne le 17 septembre 2013, consulté le 22 septembre 2020. URL : http://journals.openedition.org/ hommesmigrations/2527 ; DOI : https://doi.org/10.4000/hommesmigrations.2527

Ce document a été généré automatiquement le 22 septembre 2020.

Tous droits réservés 


\title{
Frédéric Ciriez, Mélo
}

Paris, Verticales, 2013, 325 p., 20,00€

\author{
Mustapha Harzoune
}

\section{RÉFÉRENCE}

Frédéric Ciriez, Mélo, Paris, Verticales, 2013, 325 p., 20,00€.

1 Un syndicaliste suicidaire, un immigré congolais conducteur de benne à ordures et roi de la sape, une Française d'origine chinoise championne de la vente au détail sur les trottoirs de la capitale. Trois personnages et trois récits pour une unité de lieu : Paris, symbole de ces villes-mondes, kaléidoscopiques, bigarrées, ethnicisées, individualisées, espace de l'intersection et des bifurcations, de l'ombre et de la lumière. La ville se montre ici à travers les vitres d'une Xantia, du haut d'un camion benne ou à la vitesse des rollers qui filent de rue en rue. Il y a le Paris côté jour et le Paris de la nuit ; le Paris illuminé des Grands Boulevards et celui sale et malodorant des ordures ; le Paris de la " rue du faubourg Saint-Denis, la rue du monde entier" et celui d'une histoire oubliée au 14, rue de Paradis ; le Paris cosmopolite des enseignes et des commerces, des populations et des quartiers, le Paris des juifs, Kabyles, Russes, Africains, Turcs, Chinois, Bangladais et celui du populo, de la resquille, des toutous à sa mémère et de la flicaille en civil, de la prostitution version africaine ou version asiatique, le Paris "hype" et celui des bouisbouis ; le Paris des humanités séparées, celui des mannequins anorexiques et celui d'un syndicaliste romantique et dépressif.

2 Unité de lieu et unité de temps. En cette veille de $1^{\text {er }}$ Mai, un syndicaliste lorientais décide d'en finir quand "Parfait de Paris", maître es-sapologie, prince de l'élégance, se prépare pour son heure de gloire à la grande soirée de "la lutte à mort des paraître". Moment grandiose, éblouissant, de défis vestimentaires et de joutes oratoires, sur une bande-son tout en rumbas. Au même moment, la jeune Barbara Xiao tient les comptes de son commerce et de ses désillusions amoureuses.

3 Trois titres enfin pour trois récits: "Transfixion", "Transformation" et "Transaction" qui scandent autant d'identités. Une, anonyme, marquée par le souci de l'autre et la quête 
de liberté devenue socialement invisible. L'autre, cachée derrière un surnom et qui fait dire : "Quinze ans que je suis en France et c'est ça le résultat. Je ne suis qu'un émigré esthétique, incompris du petit peuple blanc dégénéré." La dernière, insaisissable, métissée de Barbara Xiao. Des identités qui se retrouvent dans les trajectoires urbaines des trois protagonistes : périphérique, à contresens et en contresens ou tout en zigzag.

4 Ce qui relie ces personnages ? Des SMS, un briquet, une ou deux rues à Paris et à SaintOuen, un après-midi au cinéma. Autant dire pas grand-chose.

5 Frédéric Ciriez déploie un sens du détail et de l'observation, une précision chirurgicale portant aussi bien sur les qualités techniques d'une moto, les critères de l'élégance façon sapeur ou l'industrie des déchets urbains. Le style, affûté, se déploie à partir d'un travail d'orfèvre, particulièrement documenté, où la langue elle-même devient un objet traduisant la marche du monde Il lui suffit de quelques phrases, quelques images, des faits et des lieux pour incarner trois individualités. L'écriture cinématographique progresse à coups de projecteur, de flashs, de retours en arrière, de plans larges. Pas de discours sur l'immigration ou l'intégration, pas d'approche psychologisante ou sociologique, du concret, rien que du concret : un couteau de boucher, une Dunhill, une fragrance d'Antaeus de Chanel, une plongée dans le Triangle d'or d'Aubervilliers, un briquet... et se dessine le visage d'une société. Mélo est un roman taoïste où les vides disent les pleins, où les connexions et les entailles du monde passent par un jeu de miroir où se reflètent autant de convergences que de bifurcations. C'est ce qui fait que l'écriture de Ciriez est une écriture poétique, qui libère l'imaginaire et agite les neurones. 